\title{
Revascularization of the lateral wall: Long-term angiographic and clinical results of radial artery versus right internal thoracic artery grafting
}

\author{
Antonio Maria Calafiore, MD \\ Michele Di Mauro, MD \\ Stefano D'Alessandro, MD \\ Giovanni Teodori, MD \\ Giuseppe Vitolla, MD \\ Marco Contini, MD \\ Angela Lorena lacò, MD \\ Giuseppe Spira, MD
}

\footnotetext{
From the Department of Cardiology and Cardiac Surgery, University “'G. D'Annunzio," Chieti, Italy.

Read at the Eighty-first Annual Meeting of The American Association for Thoracic Surgery, San Diego, Calif, May 6-9, 2001.

Received for publication May 15, 2001; revisions requested July 11, 2001; revisions received Aug 2, 2001; accepted for publication Aug 3, 2001.

Address for reprints: Antonio Maria Calafiore, MD, "G. D'Annunzio" University, Division of Cardiac Surgery, c/o S. Camillo de' Lellis Hospital, via C. Forlanini, 50 66100 Chieti Italy (E-mail: calafiore@ unich.it).

J Thorac Cardiovasc Surg 2002;123:225-31

Copyright (C) 2002 by The American Association for Thoracic Surgery $0022-5223 / 2002 \$ 35.00+0 \quad \mathbf{1 2 / 6 / 1 1 9 7 0 4}$ doi:10.1067/mtc.2002.119704
}

Objective: We sought to evaluate whether the radial artery provides the same results as the right internal thoracic artery in lateral wall revascularization in the long term.

Methods: From January 1992 to September 1996, 288 patients had myocardial revascularization with the left internal thoracic artery anastomosed to the left anterior descending coronary artery. The lateral wall was grafted with the radial artery in 139 patients (group A) and with the right internal thoracic artery in 149 patients (group B). Groups were different only because of older age and a higher incidence of patients requiring urgent treatment in group $\mathrm{A}$. Y grafting was used in $86.4 \%$ of patients in group A and in $34.8 \%$ of patients in group B $(P<.001)$. Anastomoses per patient were similar in both groups $(3.2 \pm 0.8$ vs $3.2 \pm 0.9, P=1.000)$.

Results: Thirty-day mortality was similar ( $2.1 \%$ vs $2.0 \%, P=.722)$. There were 15 late deaths in group A versus 11 in group B $(P=.418)$. Cause of death was cardiac related in 6 patients in group A versus 7 in group B. Late redo or percutaneous transluminal coronary angioplasty was performed in 3 patients in group $\mathrm{A}$ and in 1 patient in group B $(P=0.538)$. Eight-year survival was $86.7 \% \pm 2.9 \%$ in group A versus $89.6 \% \pm 2.8 \%$ in group B $(P=.477)$; event-free survival was $84.2 \% \pm 3.2 \%$ versus $88.9 \% \pm 2.9 \%$, respectively $(P=.430)$. The patency rate within 30 days was $99.1 \%$ in group A $(105 / 106$ left internal thoracic artery plus radial artery anastomoses) versus $100 \%$ in group B (52/52 bilateral internal thoracic artery anastomoses; $P=.715)$. After a mean of $35 \pm 28$ months, the patency rate was $99.0 \%$ in group A (100/101 left internal thoracic artery plus radial artery anastomoses) and $100 \%$ in group B (33/33 bilateral internal thoracic artery anastomoses, $P=.560)$.

Conclusion: In the long-term, lateral wall grafting with the radial artery provides the same clinical and angiographic results as right internal thoracic artery grafting.

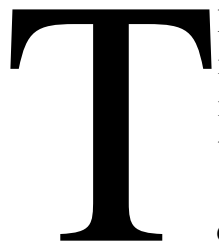

he use of the radial artery (RA) as a graft for myocardial revascularization has become widely accepted because of good early and midterm results. ${ }^{1-6}$ This graft is used in all the territories, with particular regard to the lateral wall.

The increasing use of the right internal thoracic artery (RITA) was due to recent reports that focused on the improved quality of the late 
TABLE 1. Preoperative data

\begin{tabular}{|c|c|c|c|}
\hline & Group $A(n=139)$ & Group $B(n=149)$ & $P$ value \\
\hline Age (y) & $62.8 \pm 7.9$ & $60 \pm 8.6$ & .003 \\
\hline$\geq 75 y$ & $4(2.9 \%)$ & $5(3.3 \%)$ & .885 \\
\hline Female sex & $15(10.7 \%)$ & $17(11.4 \%)$ & .999 \\
\hline Diabetes & $35(25.1 \%)$ & $38(27.3 \%)$ & .772 \\
\hline Urgent & $54(38.8 \%)$ & $39(26.2 \%)$ & .03 \\
\hline Previous AMI & $89(64 \%)$ & $84(60.4 \%)$ & .612 \\
\hline Redo operation & $7(5.0 \%)$ & $6(4.0 \%)$ & .901 \\
\hline $\mathrm{EF}$ & $59 \pm 11.8$ & $57.4 \pm 13.9$ & .295 \\
\hline$\leq 35 \%$ & $6(4.3 \%)$ & $11(7.3 \%)$ & .405 \\
\hline 2-vessel disease & $25(17.9 \%)$ & $28(18.8 \%)$ & .964 \\
\hline 3-vessel disease & $114(82.1 \%)$ & $121(81.2 \%)$ & .964 \\
\hline Left main stem & $18(12.9 \%)$ & $19(12.7 \%)$ & .9 \\
\hline
\end{tabular}

$A M I$, Acute myocardial infarction; $E F$, ejection fraction.

\section{TABLE 2. Technical data}

\begin{tabular}{lccc}
\hline & Group A (n = 139) & Group B (n = 149) & P value \\
\hline Anastomoses/patient & $3.2 \pm 0.8$ & $3.2 \pm 0.9$ & 1 \\
CPB time (min) & $68.4 \pm 20.8$ & $63.7 \pm 19$ & .011 \\
Aortic crossclamping & $53.9 \pm 16.2$ & $53.3 \pm 16.1$ & .753 \\
$\quad$ time (min) & & & \\
LITA & $139(100 \%)$ & $149(100 \%)$ & - \\
RITA & $38(27.3 \%)$ & $149(100 \%)$ & $<.001$ \\
RA & $139(100 \%)$ & $5(3.3 \%)$ & $<.001$ \\
RGEA & $47(33.8 \%)$ & $63(42.3 \%)$ & .173 \\
IEA & $15(10.7 \%)$ & $4(2.7 \%)$ & .011 \\
SVG & $13(9.3 \%)$ & $8(5.4 \%)$ & .296 \\
TAMR & $126(90.6 \%)$ & $141(94.6 \%)$ & .282
\end{tabular}

CPB, Cardiopulmonary bypass; RGEA, right gastroepiploic artery; IEA inferior epigastric artery; $S V G$, saphenous vein graft; $T A M R$, total arterial myocardial revascularization.

results when both thoracic arteries are used. ${ }^{7,8}$ Even if some of these statements need to be confirmed by further studies, it seems reasonable that grafting the left coronary system with both thoracic arteries can provide better long-term results.

We reviewed our experience to evaluate the long-term results of the use of the RA or RITA in the lateral wall.

\section{Materials and Methods}

From January 1992 to September 1996, 288 patients underwent myocardial revascularization with the left internal thoracic artery (LITA) anastomosed to the left descending thoracic artery (LAD). The lateral wall was grafted with the RA in 139 patients (group A) and with the RITA in 149 patients (group B). Groups were basically similar, but age and incidence of urgent cases were higher in group A. Some clinical characteristics are shown in Table 1.
TABLE 3. Results

\begin{tabular}{lccc}
\hline & Group A (n = 39) & Group B (n = 149) & P value \\
\hline Deaths & $3(2.1 \%)$ & $3(2.0 \%)$ & .722 \\
CVA & $2(1.4 \%)$ & $3(2.1 \%)$ & .998 \\
AMI & $1(0.7 \%)$ & $1(0.7 \%)$ & .479 \\
Early major events & $6(4.3 \%)$ & $6(4.3 \%)$ & .771 \\
Inotropes & $2(1.4 \%)$ & $2(1.4 \%)$ & .616 \\
CK-MB peak & $48 \pm 54$ & $47 \pm 41$ & .845 \\
Bleeding (mL/12 h) & $597 \pm 304$ & $546 \pm 323$ & .182 \\
Transfused patients & $44(31.6 \%)$ & $29(20.9 \%)$ & .053 \\
Atrial fibrillation & $20(14.6 \%)$ & $31(22.3 \%)$ & .127 \\
Sternal wound problem & $6(4.3 \%)$ & $4(2.7 \%)$ & .675 \\
Hospital stay (d) & $8.2 \pm 8.3$ & $5.9 \pm 2.6$ & .001 \\
ICU stay (h) & $30.6 \pm 20$ & $27.6 \pm 37.1$ & .399
\end{tabular}

$C V A$, Cerebrovascular accident; $A M I$, acute myocardial infarction; $C K$ $M B$, creatine kinase muscle brain; $I C U$, intensive care unit.

Table 2 shows some technical details, as well as the conduits used in both groups.

The number of anastomoses per patient performed on the lateral wall was similar in both groups $(1.13 \pm 0.3$ in group A vs 1.16 \pm 0.4 in group $\mathrm{B}, P=.475)$. The RA was used for sequential anastomoses $34(24.4 \%)$ times, and the RITA was used $29(19.5 \%)$ times $(P=.388)$

The RA was used in the presence of a stenosis of $70 \%$ or greater, with expected high runoff (no previous myocardial infarction and target coronary vessel of reasonable size). The RITA was used in younger patients when there was no indication for the RA or according to the surgeon's preference.

\section{Surgical Technique}

The RA was evaluated in all cases with the Allen test, and results were considered negative when hand vascularization became normal in less than 6 seconds. The graft was harvested only from the nondominant forearm. The RA was dissected through a skin incision starting $3 \mathrm{~cm}$ proximal to the wrist and ending $3 \mathrm{~cm}$ distal to the elbow. All the side branches were occluded with Hemoclip devices (Weck Closure Systems, Research Triangle Park, NC) or ligated. The RITA was harvested as a pedicle in 26 patients and skeletonized in 123 patients. Surgical technique has already been reported. ${ }^{9}$

In group A the RA was proximally anastomosed to the LITA in 120 patients and to the ascending aorta in 19 patients. When the aorta was the RA blood source, the proximal anastomosis was performed during crossclamping. When possible, a papaverine solution $(1 \mathrm{mg} / 1 \mathrm{~mL})$ was injected inside the RA graft, which was then distally clipped to allow pharmacologic dilation.

The LITA was used in all cases as an in situ graft. The RITA was used in situ in 91 patients and as a free graft in the remaining 58 patients (ie, as a $\mathrm{Y}$ graft from the LITA in 53 patients and directly from the aorta in 5 patients). The surgical technique of $Y$ grafting has already been described. ${ }^{10,11}$ When in situ, all the RITAs reached the lateral wall by passing over the aorta.

All the patients were operated on with cardiopulmonary bypass and intermittent antegrade warm blood cardioplegia. ${ }^{12}$ 
TABLE 4. Causes of late death

\begin{tabular}{lccc}
\hline & Group A $(\mathbf{n}=\mathbf{1 3 6})$ & Group B $(\mathbf{n}=\mathbf{1 4 6})$ & $\boldsymbol{P}$ value \\
\hline Cardiac & $6(44.4 \%)$ & $7(4.8 \%)$ & .901 \\
AMI & 5 & 2 & \\
Sudden death & 5 & 4 & \\
Congestive heart failure & 0 & 1 & \\
Noncardiac & $9(6.6 \%)$ & $4(2.7 \%)$ & .200 \\
Gastric hemorrhage & 1 & 0 & \\
Malignancy & 7 & 1 & \\
Stroke & 1 & 3 & \\
Total & $15(11.0 \%)$ & $11(7.5 \%)$ & .418 \\
\hline
\end{tabular}

$A M I$, Acute myocardial infarction.

\section{Postoperative Course}

From the operating room, patients were admitted to the intensive care unit and from there to the regular ward. They were followed up in our outpatient clinic 3, 6, and 12 months after their operations and each year thereafter. The more recent information was obtained by calling the patients or the referring cardiologist. If patients agreed, a coronary angiogram was performed during a brief hospitalization. The quality of the anastomoses was graded according to the method of FitzGibbon and colleagues. ${ }^{13}$ Followup was $100 \%$ complete.

\section{Statistical Analysis}

Results are expressed as mean values \pm SD unless otherwise indicated. Statistical analysis comparing 2 groups was performed with unpaired 2-tailed $t$ testing for means or with the $\chi^{2}$ test for categorical variables. Survival and event-free survival curves were obtained with the Kaplan-Meier method (SPSS software; SPSS, Inc, Chicago, Ill). The statistical significance was calculated with the log rank test.

\section{Results}

Table 3 shows some postoperative data. Six (2.1\%) patients died during the postoperative course: $3(2.1 \%)$ in group A and $3(2.0 \%)$ in group B $(P .722)$. Causes of death were intestinal bleeding $(n=1)$ and acute myocardial infarction $(n=1)$ in group A and intestinal ischemia $(n=1)$, acute mediastinitis ( $n$ $=1)$, and acute myocardial infarction $(n=1)$ in group $B$. There was no difference in the incidence of acute myocardial infarction, cerebrovascular accidents, and atrial fibrillation or in the amount of bleeding. However, the transfusion rate was higher in group A than in group B $(31.6 \%$ vs $20.9 \%, P=$ .053). Mean intensive care unit stay was similar in both groups, whereas mean hospital stay was higher in group A.

All the patients were discharged home with $60 \mathrm{mg}$ of oral diltiazem taken 3 times a day for 1 month and $100 \mathrm{mg}$ of aspirin taken once a day.

\section{Follow-up}

Twenty-six (9.2\%) patients died after a mean of $27 \pm 22$ months (minimum-maximum, 2-70 months): 15 in group A
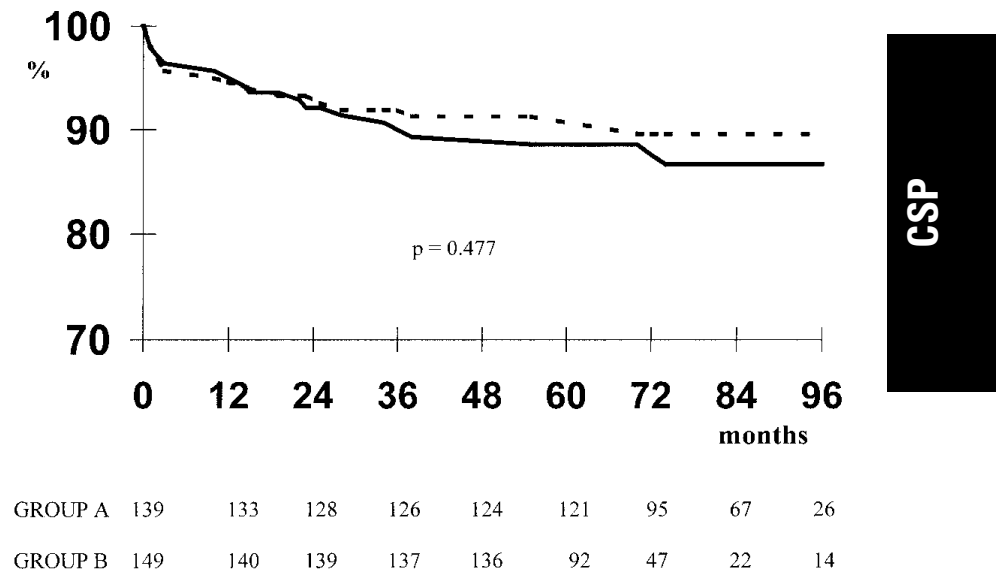

Figure 1. Eight-year actuarial survival: group A (solid lines) versus group B (dashed lines).

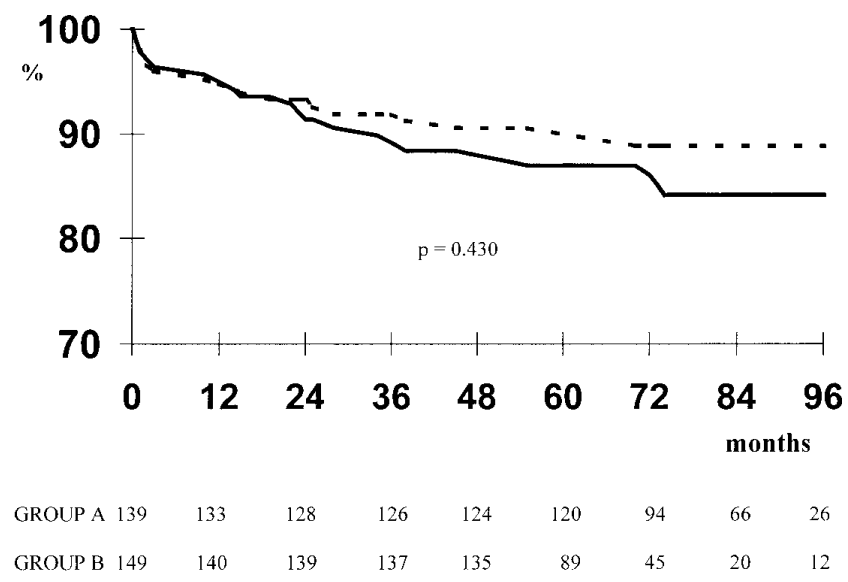

Figure 2. Eight-year event-free survival: group A (solid lines) versus group B (dashed lines).

and 11 in group B. Causes of deaths (Table 4) were cardiac in 13 patients ( 6 in group $\mathrm{A}$ and 7 in group $\mathrm{B}, P=.901$ ) and noncardiac in the remaining 13 patients ( 9 in group $A$ and 4 in group $\mathrm{B}, P=.200)$. Nine years after the operation, 8 -year survival was $88.1 \% \pm 2.0 \%$ (group A: $86.7 \% \pm 2.9 \%$ vs group B: $89.6 \% \pm 2.8 \%, P=.477$, Figure 1$)$.

Mean follow-up of the 256 survivors was $77 \pm 16$ months (range, 54-110 months). After a mean interval of 41 \pm 30 months after the operation, 4 patients (3 in group $\mathrm{A}$ and 1 in group B) needed a redo operation (surgical in 1 patient in group $\mathrm{A}$ and interventional in the remaining 3 patients [2 in group A and 1 in group B]). Eight-year eventfree survival was $86.3 \% \pm 2.2 \%$ (group A: $84.2 \% \pm 3.2 \%$ vs group B: $88.9 \% \pm 2.9 \%, P=.430$, Figure 2 ). 

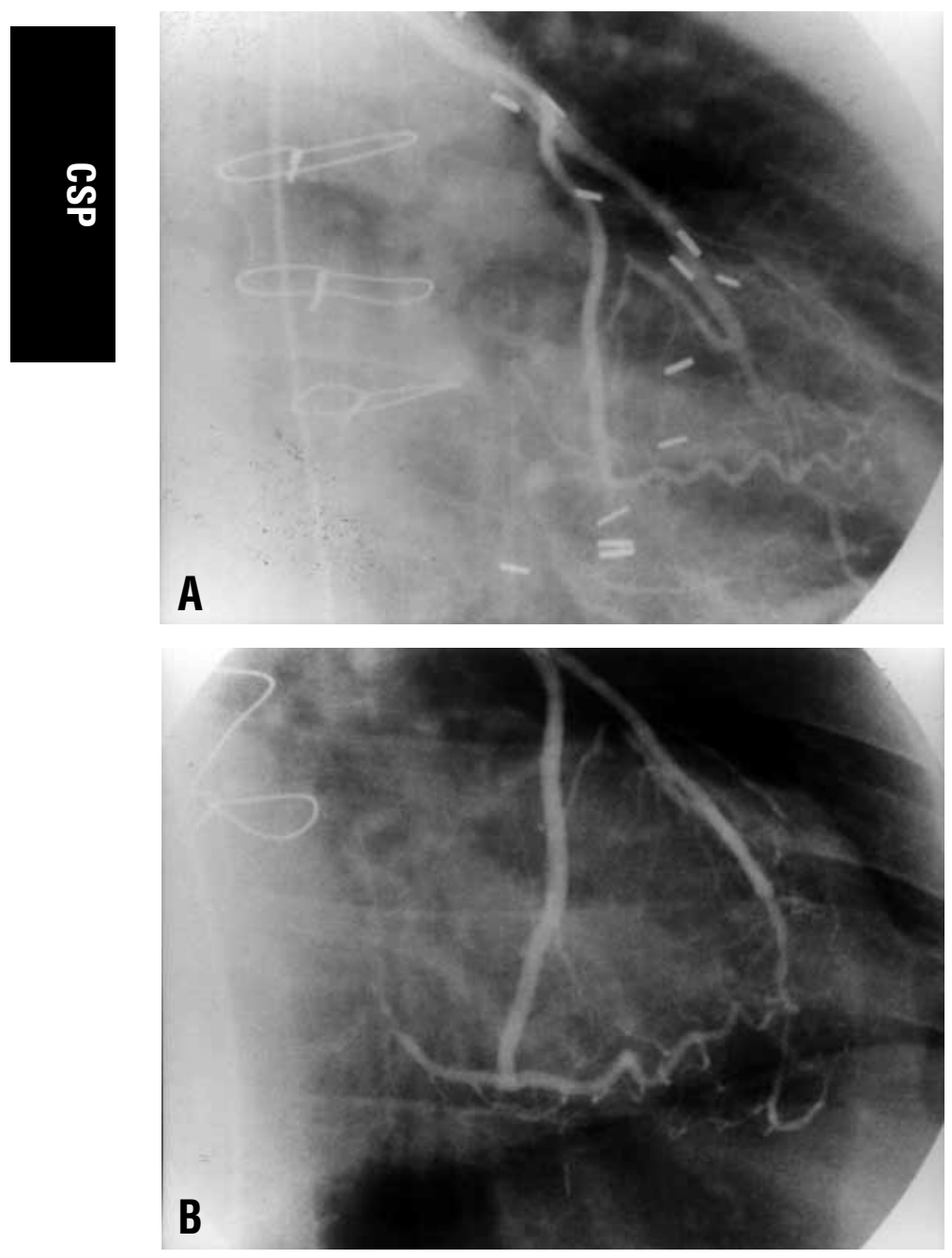

Figure 3. Postoperative angiogram. A, Eighty-five months after the operation, the RA, proximally anastomosed to the LITA, is grafted to the obtuse marginal branch. $B$, Fifty-six months after the operation, the RITA, proximally anastomosed to LITA, is grafted to the obtuse marginal branch.

\section{Angiographic Follow-up}

Sixty-eight (23.6\%) patients had an early angiogram within 30 days after the operation (mean, $8 \pm 3$ days): 46 (33.8\%) in group A and $22(15.1 \%)$ in group B. Five patients in group A and 2 in group B had both early and late angiographic studies. The quality of the anastomoses was graded according to the method of FitzGibbon and colleagues. ${ }^{13}$ The patency rate (grade A plus B) and the nonrestrictive patency rate (grade A) of LITA-RA and LITA-RITA distal anastomoses were similar: $99.1 \%(105 / 106)$ in group A and $100 \%(52 / 52)$ in group B $(P=.715)$. All the RA-LITA and RITA-LITA intermediate anastomoses were patent in the patients who had a postoperative follow-up angiogram.

\section{TABLE 5. Angiographic results}

\begin{tabular}{lccc}
\hline Conduits & Grade A & Grade B & Grade 0 \\
\hline Early: $8 \pm 3 \mathrm{~d}$ & & & \\
LITA-RA* & $105 / 106(99.1 \%)$ & $0 / 106(-)$ & $1 / 106(0.9 \%)$ \\
LITA-RITA $^{*}$ & $52 / 52(100 \%)$ & $0 / 52(-)$ & $0 / 52(-)$ \\
RA-LITA anastomoses* & $41 / 41(100 \%)$ & $0 / 41(-)$ & $0 / 51(-)$ \\
RITA-LITA anastomosest & $22 / 22(100 \%)$ & $0 / 22(-)$ & $0 / 22(-)$ \\
RITA* & $12 / 12(100 \%)$ & $0 / 12(-)$ & $0 / 12(-)$ \\
RGEA & $19 / 20(95 \%)$ & $0 / 20(-)$ & $1 / 20(5 \%)$ \\
IEA & $4 / 4(100 \%)$ & $0 / 4(-)$ & $0 / 4(-)$ \\
SVG & $4 / 4(100 \%)$ & $0 / 4(-)$ & $0 / 4(-)$ \\
At 35 \pm 28 mo & & & \\
LITA-RA* & $98 / 101(97 \%)$ & $2 / 101(2 \%)$ & $1 / 101(1 \%)$ \\
LITA-RITAt & $33 / 33(100 \%)$ & $0 / 33(-)$ & $0 / 33(-)$ \\
RA-LITA anastomoses* & $40 / 40(100 \%)$ & $0 / 40(-)$ & $0 / 40(-)$ \\
RITA-LITA anastomosest & $12 / 12(100 \%)$ & $0 / 12(-)$ & $0 / 12(-)$ \\
RITA* & $5 / 5(100 \%)$ & $0 / 5(-)$ & $0 / 5(-)$ \\
RGEA & $20 / 24(83.3 \%)$ & $1 / 24(4.2 \%)$ & $3 / 24(12.5 \%)$ \\
IEA & $12 / 13(92.3 \%)$ & $0 / 13(-)$ & $1 / 13(7.7 \%)$ \\
SVG & $11 / 12(91.7 \%)$ & $0 / 12(-)$ & $1 / 12(8.3 \%)$ \\
\hline
\end{tabular}

RGEA, Right gastroepiploic artery; IEA, inferior epigastric artery; SVG, saphenous vein graft.

${ }^{*}$ Group A.

tGroup B.

After a mean of $35 \pm 28$ months (range, 6-95 months), 57 (22.5\% of the survivors) patients had a new angiogram. The patency rate (grade A and B) of the LITA-RA anastomoses was 99\% (100/101) (Figure 3, A), which is similar to the patency rate of the LITA-RITA anastomoses (100\% [33/33], $P=.560$; Figure 3, $B$ ). Grade A anastomoses were 97\% for the LITA-RA anastomoses and $100 \%$ for the LITARITA anastomoses $(33 / 33, P=.740)$. All the RA-LITA and RITA-LITA intermediate anastomoses were fully patent. Table 5 summarizes the angiographic results. In this cohort of patients, no RAs showed a string sign.

\section{Discussion}

The use of the RA as a graft for myocardial revascularization started in the $1970 \mathrm{~s}^{14}$ but was discontinued because of the high occlusion rate..$^{15}$ Acar and colleagues ${ }^{1}$ successfully reproposed this conduit in the early 1990s. Good midterm clinical and angiographic results were reported, $2,3,5,6,11,16-23$ and today the RA is a popular conduit.

When bilateral ITA grafting become more diffuse, the problem of the correct use of the RITA was predominant. The in situ RITA to the right coronary artery system was proved to have the same outcome as the saphenous vein graft. ${ }^{24}$ Grafting the in situ RITA to the LAD forces the conduit to cross the midline in a very dangerous manner at the level of the aortic valve and of the pulmonary infundibulum. Bringing the RITA to the lateral wall is less dangerous. The 
retroaortic route was proposed by Puig and colleagues ${ }^{25}$ and was demonstrated to be safe by many authors. ${ }^{26,27}$ The overaortic route passes very high at the distal ascending aorta and can be covered by the thymic fat. It seems to be less dangerous in case of a resternotomy.

However, the increased use of the RITA was related to its use as a free graft, not from the aorta (its patency rate is significantly lower than the in situ graft) ${ }^{28}$ but connected to the LITA as a $\mathrm{T}^{29}$ or a $\mathrm{Y}^{10}$ composite graft.

With the LAD as the target vessel for the LITA, the use of the RITA is directed mainly to the lateral wall. Because this territory is also the main target of RA grafting, we retrospectively analyzed 2 groups of patients, all with a LITA to the LAD and a RITA or an RA in the lateral wall.

Our study showed that, after a mean follow-up of $77 \pm$ 16 months, it was not possible to find any difference between the 2 groups, in terms of both early and late clinical results. Angiographic results were also similar and, after a mean of $35 \pm 28$ months, comparing LITA-RA and LITARITA anastomoses, the patency rate was $99 \%$ versus $100 \%$, and the nonrestrictive patency rate was $97 \%$ versus $100 \%$. Interestingly, the intermediate anastomoses between the RA or the RITA with the LITA were all patent, demonstrating that the addition of an anastomosis does not impair the possibility of a satisfying late patency rate.

In our experience no RA showed a string sign. It is difficult to understand why. The only possibility is that we tried to follow carefully, since the beginning, strict indications for RA grafting. Royse and colleagues ${ }^{30}$ demonstrated that string sign is related to a low-grade coronary stenosis of the target vessel $(56 \% \pm 5 \%)$. Since the first articles we published on this topic, ${ }^{2}$ we believed that the RA had to be used only if a severe stenosis was present, and we carefully followed this policy in all cases. Furthermore, it is possible that patients who refused a new angiogram could have this abnormality. However, it seems that, after the first months after the operation, the RA loses its peculiar characteristics of increased vasomotricity, ${ }^{3}$ and this can be at the basis of the reduced incidence of this angiographic aspect of the RA graft.

In conclusion, after a maximum follow-up of 8 years, clinical and angiographic results of RA and RITA grafting in the lateral wall, if the LITA is anastomosed to the LAD, are similar. This fact enhances the possibility of choice of the appropriate graft when coronary revascularization with multiple arterial grafting is scheduled.

\section{References}

1. Acar C, Jebara VA, Portoghese M, Beyssen B, Pagny JY, Grare P, et al. Revival of the radial artery for coronary artery bypass grafting. Ann Thorac Surg. 1992;54:652-60.

2. Calafiore AM, Teodori G, Di Giammarco G, D'Annunzio E, Angelini $\mathrm{R}$, Vitolla $\mathrm{G}$, et al. Coronary revascularization with the radial artery: new interest in an old conduit. J Card Surg. 1995;10:140-6.
3. Possati GF, Gaudino M, Alessandrini F, Luciani N, Glieca F, Trani C, et al. Midterm clinical and angiographic results of radial artery grafts used for myocardial revascularization. J Thorac Cardiovasc Surg. 1998;116:1015-21.

4. Acar C, Ramsheyi A, Pagny JY, Jebara VA, Pascal B, Fabiani JN, et al. The radial artery for coronary bypass grafting: clinical and angiographic results at five years. J Thorac Cardiovasc Surg. 1998;116: 981-9.

5. Royse AG, Royse CF, Raman JS. Exclusive Y graft operation for multivessel coronary revascularization. Ann Thorac Surg. 1999;68:1612-8.

6. Iacò AL, Teodori G, Di Giammarco G, Di Mauro M, Storto L, Mazzei $\mathrm{V}$, et al. Radial artery for myocardial revascularization: long-term clinical and angiographic results. Ann Thorac Surg. 2001;72:464-8.

7. Lytle BW, Blackstone EH, Loop FD, Houghtaling PL, Arnold JH, Akhrass R, et al. Two internal thoracic arteries are better than one. $J$ Thorac Cardiovasc Surg. 1999;117:855-72.

8. Pick AW, Orszulak TA, Anderson BJ, Schaff HV. Single versus bilateral internal mammary artery grafts: 10-year outcome analysis. Ann Thorac Surg. 1997;64:599-605.

9. Calafiore AM, Vitolla G, Iacò AL, Fino C, Di Giammarco G, Marchesani F, et al. Bilateral internal mammary artery grafting: midterm results of pedicled versus skeletonized conduits. Ann Thorac Surg. 1999;67:1637-42.

10. Calafiore AM, Contini M, Vitolla G, Di Mauro M, Mazzei V, Teodori $\mathrm{G}$, et al. Bilateral internal thoracic artery grafting: long-term clinical and angiographic results of in situ versus Y grafts. $J$ Thorac Cardiovasc Surg. 2000;120:990-8.

11. Calafiore AM, Di Giammarco G, Luciani N, Maddestra N, Di Nardo $\mathrm{E}$, Angelini R, et al. Composite arterial conduits for a wider arterial myocardial revascularization. Ann Thorac Surg. 1994;58:185-90.

12. Calafiore AM, Teodori G, Mezzetti A, Bosco G, Verna AM, Di Giammarco G, et al. Intermittent antegrade warm blood cardioplegia. Ann Thorac Surg. 1995;59:398-402.

13. Fitzgibbon GM, Kafka HP, Leach AJ, Keon WJ, Hooper GD, Burton JR. Coronary bypass graft fate and patient outcome: angiographic follow-up of 5,065 grafts related to survival and re-operation in 1,388 patients during 25 years. J Am Coll Cardiol. 1996;28:616-26.

14. Carpentier A, Guermonprez JL, Deloche A, Frechette C, Dubost C. The aorta-to-coronary radial artery bypass graft: a technique avoiding pathological changes in grafts. Ann Thorac Surg. 1973;16:111-21.

15. Geha AS, Krone RJ, McCormik JR, Baue AE. Selection of coronary bypass anatomic, physiological, and angiographic considerations of vein and mammary artery grafts. J Thorac Cardiovasc Surg. 1975; 70:414-31.

16. Dietl CA, Benoit $\mathrm{CH}$. Radial artery graft for coronary revascularization: technical considerations. Ann Thorac Surg. 1995;60:102-10.

17. Calafiore AM, Di Giammarco G, Teodori G, D'Annunzio E, Vitolla G, Fino C, et al. Radial artery and inferior epigastric artery in composite grafts: improved midterm angiographic results. Ann Thorac Surg. 1995;60:517-24.

18. da Costa FDA, da Costa IA, Poffo R, Abucharin D, Gaspar R, Garcia $\mathrm{L}$, et al. Myocardial revascularization with the radial artery: a clinical and angiographic study. Ann Thorac Surg. 1996;62:475-80.

19. Manasse E, Sperti G, Suma H, Canosa C, Kol A, Martinelli L, et al. Use of the radial artery for myocardial revascularization. Ann Thorac Surg. 1996;62:1076-83.

20. Weinschelbaum EE, Gabe ED, Macchia A, Smimmo R, Suárez LD. Total myocardial revascularization with arterial conduits: radial artery combined with internal thoracic arteries. J Thorac Cardiovasc Surg. 1997;114:911-6.

21. Chen AM, Broadman RF, Frame R, Braver LM, Tranbaugh RF, Banks $\mathrm{T}$, et al. Routine myocardial revascularization with the radial artery: a multicenter experience. J Card Surg. 1998;13:318-27.

22. Bhan A, Gupta V, Choudhary SK, Sharma R, Singh B, Aggarwal R, et al. Radial artery in CABG: Could the early results be comparable to internal mammary artery graft? Ann Thorac Surg. 1999;67:1631-6.

23. Sundt TM III, Barner HB, Camillo CJ, Gay WA Jr. Total arterial revascularization with an internal thoracic artery and radial artery $\mathrm{T}$ graft. Ann Thorac Surg. 1999;68:399-405.

24. Carrel T, Hurber P, Turina M. Operation for two-vessel coronary 
artery disease: midterm results of bilateral ITA grafting versus unilateral ITA and saphenous vein grafting. Ann Thorac Surg. 1996;62: 1289-94.

25. Puig JB, Neto LF, Rati M, Ramires JAF, Luz PL, Pileggi F, et al. A technique of anastomosis of the right internal mammary artery to the circumflex artery and to its branches. Ann Thorac Surg. 1984;38:533-4.

26. Ura M, Sakata R, Nakayama Y, Arai Y, Oshima S, Noda K. Analysis by early angiography of right internal thoracic artery grafting via the transverse sinus: predictors of graft failure. Circulation. 2000;101: 640-6.

27. Buche M, Schroeder E, Chenu P, Gurne O, Marchandise B, Pompilio $\mathrm{G}$, et al. Revascularization of the circumflex artery with the pedicles right internal thoracic artery: clinical, functional, and angiographic midterm results. J Thorac Cardiovasc Surg. 1995;110:1338-43.

28. Buxton BF, Ruengsakulrach P, Fuller J, Rosalion A, Reid CM, Tatoulis $\mathrm{J}$. The right internal thoracic artery graft-benefits of grading the left coronary system and native vessels with a high grade stenosis. Eur J Cardiothorac Surg. 2000;18:255-61.

29. Tector AJ, Amundsen S, Schmahl TM, Kress DC, Peter M. Total revascularization with T grafts. Ann Thorac Surg. 1994;57:33-9.

30. Royse AG, Royse CF, Tatoulis J, Grigg LE, Shah P, Hunt D, et al. Postoperative radial artery angiography for coronary bypass surgery. Eur J Cardiothorac Surg. 2000;17:294-304.

\section{Discussion}

Dr Alfred Tector (Milwaukee, Wis). After it was shown that bypassing the LAD with the LITA significantly enhanced longterm survival after coronary bypass operations, some surgeons became interested in multiple or total coronary artery revascularization as an attempt to enhance outcomes. Dr Calafiore and his associates have demonstrated excellent survival and a reduced need for reintervention in 288 patients who were revascularized with multiple arterial bypass grafts. The authors accomplished near-perfect graft patency, as demonstrated with angiography, when using either the RITA or the RA to bypass the coronary arteries supplying the lateral wall of the heart in 68 patients studied 5 to 11 days and 57 patients observed 7 to 63 months after their operation. This occurred whether the proximal end of the RA or the RITA was connected to the LITA or the aorta or whether it was used as an in situ graft. The authors do not list the patency of the LITA-LAD anastomoses; however, I assume it is similar to that of the lateral wall grafts.

I have several questions for Dr Calafiore. What percentage of total patients undergoing coronary bypass grafting by your group does this series of patients represent? Were any of the patients in the early group who had postoperative graft visualization also studied late?

You state that coronary arteries bypassed with RA grafts were carefully selected and had $70 \%$ stenosis or greater and were larger and had good runoff. Other than the younger patients mentioned in the manuscript, what were your criteria for choosing the RITA grafts?

What technical and selective features do you think were most beneficial to you in obtaining outstanding patency with these grafts?

Finally, you point out that all of these revascularization procedures were performed with cardiopulmonary bypass, but I am sure many people wonder whether you think you could achieve equally good results using off-pump coronary artery bypass techniques.

Dr Calafiore. Thank you, Dr Tector, for your comments.

The patency rates of the LITA anastomosed to the LAD in this group were very high. There was only one anastomosis that had stenosis in the late angiographic study. Basically, if we compare the LITA to the RA, there is always a trend and a higher patency in the LITA instead of the RA.

In the 4 years of the study, we operated on something like 1200 patients with coronary disease. Therefore, this is not more than $20 \%$, perhaps less, of our global experience.

If I understood correctly, you asked whether I think I can achieve the same results with off-pump operations. This is an interesting question. We did not have such a long-term follow-up, but at least I can tell you that in our experience today, $50 \%$ or more of the patients who have a total arterial revascularization have offpump operations. When we have the time to better understand the midterm or long-term results, I will be able to answer your question, but at this moment, there is no difference between the 2 groups.

You had one other question, Dr Tector.

Dr Tector. The other question was what technical and selective features do you think were most beneficial to you in obtaining outstanding patency with these grafts?

Dr Calafiore. I think that the problem is also selection of the vessel. Basically, I do not believe in extensive revascularization performed with 5 or more grafts. Generally, our policy is to graft the vessels with a good size and a good territory. I think that this is just a key point for having a good patency rate. Of course, there is the technical experience of the surgeon. We must not forget that the surgeon is always a key point for a good operation.

Dr Lawrence Cohn (Brookline, Mass). In the first session of this meeting, we listened to the group in St Louis discuss the RA. What has been your experience with only moderately severe coronary stenosis using those grafts? There is a little concern that the RA for the right coronary, moderate stenosis, or both does not have great long-term patency.

Dr Calafiore. When we started to use the RA, we thought that the problem of the choice of the territory was the key point for the good patency rate of this artery. I think that our good results depend on our strict patient selection. We always preferred to use a good-sized coronary artery with severe stenosis and without myocardial infarction. I think that this is very important.

The reason for the lower patency rate in the right coronary territory is perhaps that the right coronary territory in the great majority of the patients who have operations is the most diseased because the great majority of them had a previous inferior myocardial infarction. The viable territory is not very big, and there are many small vessels. I think that a lot of grafts will fail in the right coronary territory. The circumflex territory is surely the best one, except, of course, the LAD, for an RA graft, but the LAD is the best for the LITA.

Dr Reida M. El Oakley (Singapore). Pharmacologic management of RAs is a highly controversial area. Could you please tell us how you manage the RA from the pharmacologic point of view during and after operation?

Dr Calafiore. In the beginning we were focused on the pharmacologic treatment of the patient with the RA. If you remember, the first attempts with the RA failed because of a lot of technical aspects and because the pathophysiology of the artery was not known. When the experience started again, we started to use calcium blockers extensively. Today I believe that this is not so important. Of course, during operations, we touch the conduit, but now it 
has been demonstrated that nitroglycerin is more effective than calcium blockers to relieve spasm. Today we are using nitroglycerin intravenously, and in the first weeks we are still giving calcium blockers, but I think that this aspect is not the most important issue for the patency rate of the RA. I think that the technical aspect and the choice of the correct territory is the key point for the satisfying patency rate. The pharmacologic aspect becomes less important.

Dr Brian Buxton (Heidelberg, Australia). You are a few years ahead of us with the number of RA grafts and ITA grafts that you have been performing. I have the impression that the RA does not quite match up to the free RITA, although your results here suggest that they do. If you had a crystal ball, what would you think would happen over an extended period of time?

Do you think it is just as valid to use an RA as the Y graft component, or do you think that there is still a very important role for Dr Tector's operation, in which the RITA is attached to the side of the LITA? In other words, do you think there is any difference? I know you show there is none.

Dr Calafiore. I think that today the best operation always is to use the 2 thoracic arteries, perhaps in the $\mathrm{Y}$ or $\mathrm{T}$ graft, as Dr Tector proposed. But what I think is important is the message that the RA is a second arterial conduit that can be used with very good results. I think that many surgeons will use a second conduit if this is an
RA because it has a good size and can be harvested contemporaneously with the LITA. Many surgeons will not use the RITA every day in every patient. Today my policy is still to use 2 thoracic arteries for the great majority of patients. However, I think that the knowledge that the patency rate of the RA in selected cases is pretty good is important information and a positive message to send.

Dr O. Wayne Isom (New York, NY). There was one thing you did not mention. Did you notice, in the patients with bilateral ITA harvesting, any increase in sternal infection?

Dr Calafiore. In 1994 and 1995 we completely changed the method of dissecting ITAs that were skeletonized during harvesting. It was demonstrated, both in necropsies and studying the sternal vascularization after bilateral ITA harvesting, that the skeletonization preserves the sternum from the devascularization that follows the harvesting of both ITAs. We used a lot of RAs in the first part of our experience because the RITA was not used in diabetic patients. Now we are using the RITA in all the patients who have so-called risk factors such as obesity and diabetes.

Dr Isom. You do not notice any difference in infection?

Dr Calafiore. No. There is no difference in the infection rate or in the major sternal problems in patients with 1 or 2 ITAs if skeletonized.

\section{Notice from the American Board of Thoracic Surgery regarding trainees and candidates for certification who are called to military service related to the war on terrorism}

The Board appreciates the concern of those who have received emergency call to military service. They may be assured that the Board will exercise the same sympathetic consideration as was given to candidates, in recognition of their special contributions to their country, during the Viet Nam conflict and the Persian Gulf conflict with regard to applications, examinations, and interruption of training. If you have any questions about how this might affect you, please call the Board office at 847-475-1520.

Peter C. Pairolero, MD

Chair

The American Board of Thoracic Surgery 